\title{
Prevalence of rhinitis symptoms among textile industry workers exposed to cotton dust
}

\author{
Ivan de Picoli Dantas', Fabiana Cardoso Pereira Valera², Carlos Eduardo Monteiro Zappelin, Wilma Terezinha Anselmo-Lima4. \\ 1) Otorhinolaryngologist. PhD Student, University Hospital, Faculty of Medicine of Ribeirão Preto, Universidade de São Paulo (HCFMRP-USP). \\ 2) Postdoctoral in Otorhinolaryngology. Professor, Department of Ophthalmology, Otorhinolary ngology and Head and Neck Surgery, HCFMRP-USP \\ 3) Doctor. Resident in Otorhinolaryngology, University Hospital, Faculty of Medicine, Universidade Estadual de Campinas (UNICAMP) \\ 4) Associate Professor. Department of Ophthalmology, Otorhinolaryngology and Head and Neck Surgery, HCFMRP-USP. \\ Institution: Universidade de São Paulo, Ribeirão Preto \\ Ribeirão Preto / SP - Brazil. \\ Mailing address: Ivan de Picoli Dantas - Rua Fonte da Saudade, 500 - Americana/SP-Brazil -Zip code: 13471-613-Cellular: (+55 19)9104-0400 - E-mail: ivanorl@yahoo.com.br \\ Article received in September 7, 2012. Article accepted in October 7, 2012
}

\section{SUMMARY}

Introduction: The respiratory tract is one of the main points of entry of foreign substances into the body. Because of its location, the respiratory tract is heavily exposed to harmful agents, such as gases, vapors, or aerosols.

Aim: Our objective was to evaluate the symptoms of occupational rhinitis in workers exposed to cotton dust.

Method: The prospective study population consisted of workers from the "Nova Esperança" Cooperative of Nova Odessa (Sao Paulo), who were studied between September and December 2008. Data were collected through an individually and privately answered questionnaire designed by the author considering the clinical criteria for rhinitis.

Results: Using the questionnaire, we evaluated a total of 124 workers. Among these patients, 63.7\% complained of nasal obstruction, $57.2 \%$ of nasal itching, $46.7 \%$ of rhinorrhea, and $66.1 \%$ of sneezing. Of the patients considered to have very serious symptoms, 9\% had nasal obstruction; $9 \%$, itching; $4 \%$, rhinorrhea; and 6.4\%, sneezing.

Discussion: Aerosol agents in the environment can clearly aggravate and even initiate rhinitis. From the standpoint of pathogenesis, the mechanisms of classical allergic airway inflammation involving mast cells, IgE, histamine, eosinophils, and lymphocytes may be responsible for the development of rhinitis after exposure to high molecular weight allergens such as proteins derived from animals and plants. This study showed a strong relationship between the occupational exposures associated with work in the cotton textile industry and the symptoms of rhinitis.

Conclusion: Analysis of the data clearly showed the occurrence of rhinitis symptoms in these patients, demonstrating that the prevention and treatment of this condition in the workplace is extremely important.

Keywords: Rhinitis, Cotton industry, Dust, Nasal mucosa.

\section{INTRODUCTION}

The respiratory tract is one of the main points of entry of foreign substances into the body (1). The nasal fossae represents the first point of contact with inhaled agents. Nasal fossae components activate the first defense mechanisms: air filtration and conditioning and the sensations of odors and irritants. These are important but usually underestimated functions (1).

Because of their location, the nasal fossae are highly exposed to harmful agents such as gases, vapors, and aerosols (dust, smoke, mists, and fogs). These agents may have discomforting, irritating, allergenic, or corrosive effects. Regarding the care provided to workers, it is often difficult to identify agents of an occupational nature (1). Occupational rhinitis (OR) differs from previously existing rhinitis exacerbated by work and from concomitant rhinitis (allergic and non-allergic), which may worsen with work but is not caused by it (2).
Inflammatory disease of the nasal mucosae is usually characterized by nasal obstruction and rhinorrhea, eventually accompanied by irritation, itching, and sneezing. Because of their high degree of environmental exposure and because of their more limited defense mechanisms, the nasal fossae represent one of the organic systems most vulnerable to environmental pollutants (3).

The following pre-existing conditions may facilitate the initiation of rhinitis: deviations of the nasal septum, turbinate hypertrophy, presence of nasal polyps, stenosis of the nasal fossae, choanal atresia, presence of foreign bodies, tumors and chronic rhinitis, disorders of mucociliary transport, certain systemic conditions (e.g., allergy, diabetes, endocrinopathies, collagenoses, and immunodeficiencies), use of drugs or nasal medications, contact with domestic irritants (e.g., detergents, insecticides, paints, and cotton fibers), and contact with environmental irritants (e.g., smoke, tobacco, and air conditioning) (1,3). In the current study, we investigated workers exposed only to cotton dust, which is considered 
to be an allergenic/irritant factor involved in the inflammatory process.

Although a large body of knowledge is available about the prevention and management conditions that cause symptoms such as those associated with rhinitis, companies do not always attribute the proper importance to individual protection, which can cause unnecessary harm to workers (4).

The objective of the present study was to determine the prevalence of symptoms related to rhinitis among workers employed by the "Nova Esperança" Cooperative, located in Nova Odessa (São Paulo), which specializes in cotton, during the period from September-December 2008.

\section{Method}

The present analytical, observational, cross-sectional study was approved by the Ethics Committee of the University Hospital, Faculty of Medicine of Ribeirão Preto, University of São Paulo (protocol no. 10183/2009). This study did not have any conflict of interest (5).

The study population consisted of 124 workers employed at the "Nova Esperança" Cooperative of Nova Odessa (São Paulo), evaluated between SeptemberDecember 2008. Workers who were periodically exposed to cotton dust were included in the sample after the provided written informed consent to participate in the study.

The data were collected using a questionnaire developed by the senior author based on the clinical criteria for a diagnosis of rhinitis, to which the workers responded individually and privately.

The variables used were as follows: gender (categorical: male or female), age range (quantitative numerical: years), and degree of allergic symptoms (categorical: very severe, severe, moderate, mild, or asymptomatic).

All patients were previously informed verbally and in writing about the objectives and methods of the study, as well as its voluntary nature, and confidentiality of individual information.

\section{RESULTS}

A total of 124 workers employed by the "Nova Esperança" Cooperative were evaluated between
September and December 2008. Mean age was of the subjects was 36.5 years, and $68.5 \%$ of them were women and $31.4 \%$ men. Five (4\%) workers had already undergone a nasal surgery and 6 (4.8\%) did not respond.

Seventy-nine subjects (63.7\%) had complaints of nasal obstruction, 71 (57.2\%) had nasal itching, 58 (46.7\%) reported rhinorrhea, and 82 (66.1\%) reported sneezing (Figure 1).

Among the patients with a history of nasal obstruction, only $11(9 \%)$ reported symptoms considered to be very severe, 14 (11\%) reported severe symptoms, 21 (17\%) reported moderate symptoms, and 33 (27\%) reported mild symptoms. Finally, 45 (36\%) subjects had no obstructive complaints (Figure 2).

When questioned about nasal itching, 11 (9\%) reported very severe symptoms; 16 (13\%), severe symptoms; 15 (12\%), moderate symptoms; and 29 (23\%), mild symptoms. Fifty-three subjects (43\%) did not report itching symptoms (Figure 3).

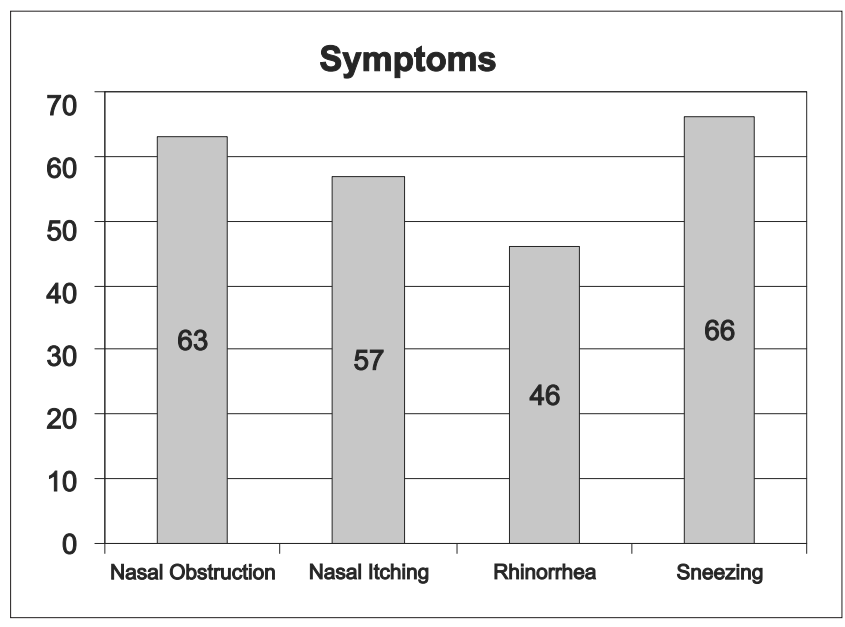

Figure 1. Rhinitis symptoms.

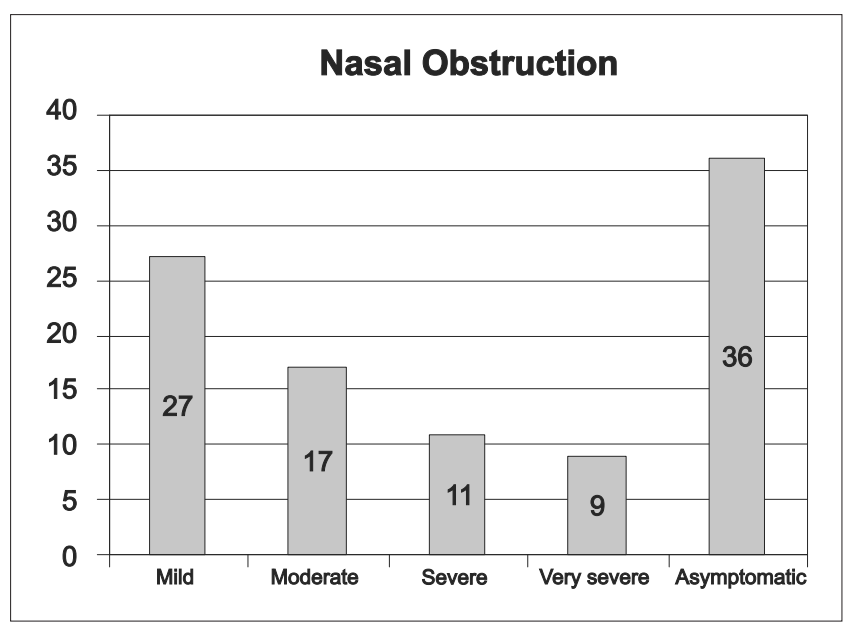

Figure 2. Degree of nasal obstruction. 


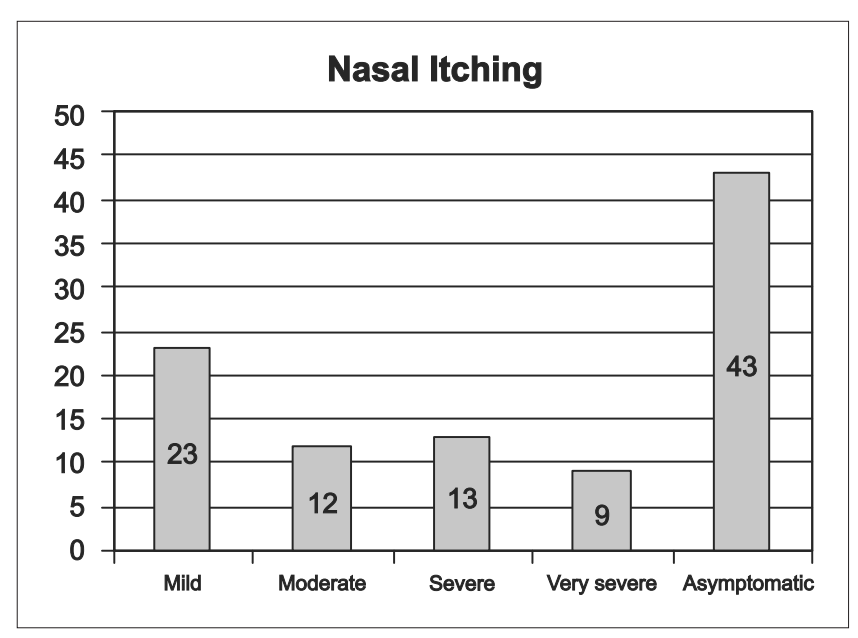

Figure 3. Degree of nasal itching.

Fifty-eight subjects (46.7\%) had rhinorrhea. Of these, 5 (4\%) reported very severe symptoms; 12 (10\%), severe symptoms; 19 (15\%), moderate symptoms; and 22 (18\%), mild symptoms. The remaining 66 (53\%) did not report this type of symptom (Figure 4).

Another symptom considered in the analysis of the questionnaire was sneezing (frequency and severity). The following data were obtained: 8 subjects (6.4\%) had very severe symptoms; 17 (13.7\%), severe symptoms; 24 (193\%), moderate symptoms; and 33 (26.6\%), mild symptoms. Forty-three subjects (34.6\%) did not report any symptoms (Figure 5).

\section{DISCUSSION}

Occupational rhinitis (OR) is characterized by the presence of nasal symptoms associated with exposure to agents of high or low molecular weight and/or irritating substances in the workplace (5). Aerosol agents in the environment may clearly aggravate and even trigger the signs and symptoms of rhinitis (6). The present study revealed a strong relationship between the occupational exposure of textile industry workers to cotton dust and rhinitis symptoms.

In a recent review, Della Giustina et al. (6) observed a strong relationship between upper airway diseases related to work and the causative agents associated with an individual's occupation, environment, and operations performed, as was also observed in the present study. The current study was conducted in order to help with the diagnosis of these diseases and to establish a connection between exposure and the symptoms detected.

OR symptoms are similar to those of other

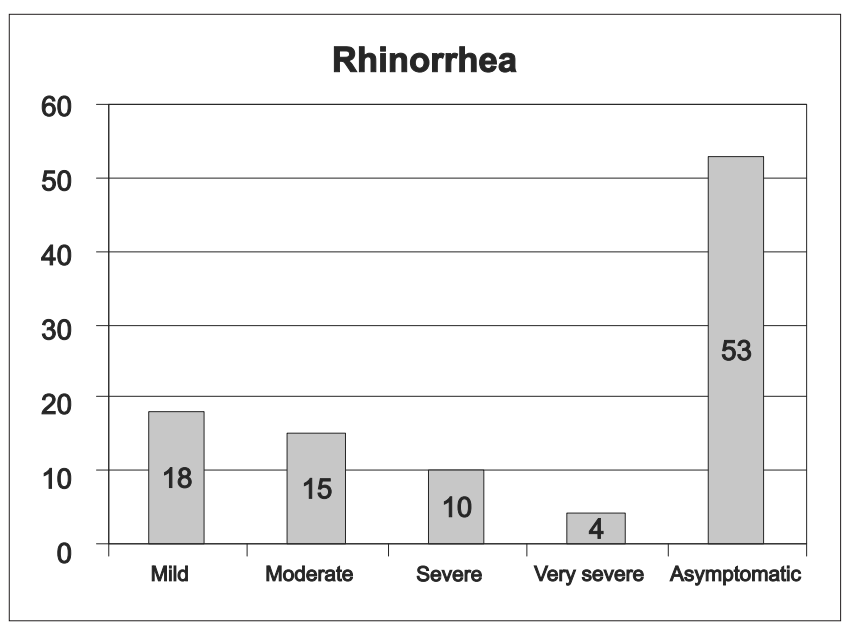

Figure 4. Degree of rhinorrhea.

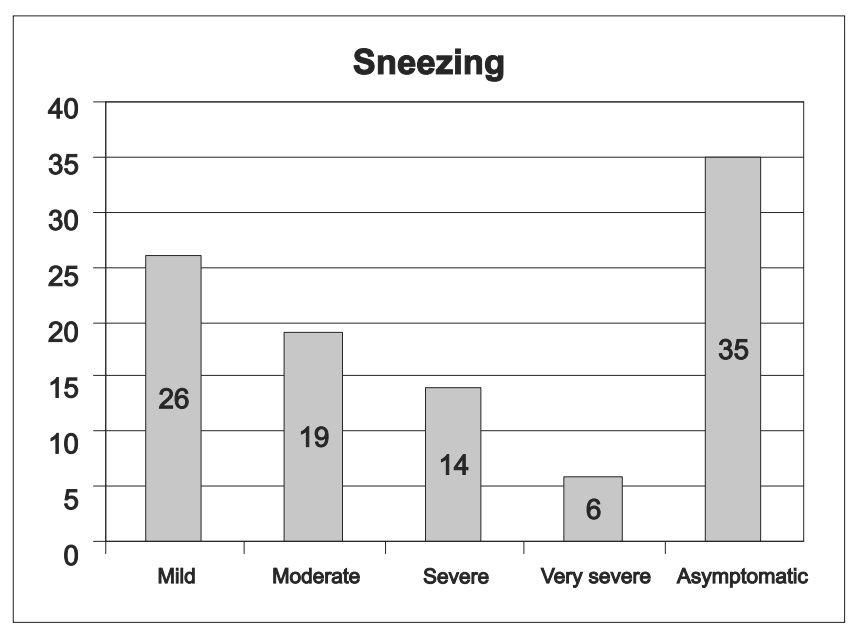

Figure 5. Degree of sneezing.

manifestations of rhinitis and result from exposure of the nasal mucosa to external stimuli in the workplace. Thus, affected individuals will present nasal congestion resulting from vasodilation and increased vascular permeability, itching and sneezing due to nervous sensory stimulation, and coryza due to gland stimulation and increased vascular permeability (2).

In 1995, BARDANA (9) suggested a classification for OR: (1) Annoying: when an individual has very high olfactory sensitivity, developing symptoms when exposed to substances such as perfumes and detergents; (2) Irritant: when nonspecific inflammation occurs in the nose without involving more elaborate or allergic immunological mechanisms; (3) Corrosive: occurring after exposure to high concentrations of soluble and irritating chemical gases such as chlorine and ammonia, which trigger intense inflammation with injury to the nasal mucosa and permanent 
changes in the physiological functions of the nose, such as olfaction; (4) Allergic (or immunological): involving IgEmediated and other mechanisms.

According to BAGATIN et al. (1), inflammatory disease of the nasal mucosa is characterized by nasal obstruction and rhinorrhea, eventually with irritation, itching, and sneezing. The incidence of job-related rhinoconjunctival symptoms is higher during the first $12-20$ months of professional activity and increases with the duration of exposure for a period of up to 24 months (2). Among the workers interviewed in the present study, the main symptom reported was sneezing, affecting $61 \%$ of the subjects, followed by nasal obstruction, which affected $63.7 \%$.

In addition to the direct irritating action of cotton dust, many other causes of rhinitis have been reported in the literature. These include acrylates, which affect workers who manufacture textiles, coatings, filters, and adhesives, and diisocyanates, which affect workers who manufacture polyurethane (foam, coatings, and sealants), textiles, and paints $(10,11)$.

According to ARRAIS (11), in view of the exposure to cotton dust and other raw materials used extensively in the textile industry, the symptoms presented by the workers may be attributed to the action of allergens. From the viewpoint of pathogenesis, classical allergic mechanisms of airway inflammation involving mast cells, IgE, histamine, eosinophils, and lymphocytes may be responsible for the development of rhinitis after exposure to high molecular weight allergens such as animal and plant proteins.

Similarly, gases and irritants can directly injure the airway epithelium, resulting in edema, inflammation, and cell death. This epithelium can mediate inflammation by releasing chemotactic factors such as interleukins (12). Thus, irritation of the airway epithelium induced by cotton dust can actually contribute to edema, inflammation, and the entire pathogenic process described earlier (3).

The estimate is that about $14,000 \mathrm{~L}$ of air circulates during the $40 \mathrm{~h} /$ week of work. If physical activity is greater, pulmonary ventilation will also be greater, with increased inhalation of undesirable substances (3).

Today rhinitis is a worldwide problem, which is exacerbated by industrial progress. The technological progress that facilitates the development of new substances for use in the textile industry increases the density of urban population and increases environmental pollution (12-13). Despite a good prognosis, the condition should not be ignored. A thorough investigation of the site should be conducted at presentation (13).
Prevention is based on environmental monitoring in order to control and attenuate exposure to causal agents (substitution, confinement, isolation, and exhaust), intervention in work organization (reduction in number of environmental stressors, number of persons exposed, and duration of exposure), practice of body and environmental hygiene, periodic medical examinations, training, and use of individual protective equipment (masks, respirators, filters, and air supplies) $(3,4)$.

\section{CONCLUSION}

Analysis of the data clearly shows that these patients have symptoms of rhinitis, demonstrating that prevention and treatment of this condition in the workplace is extremely important in order to reduce the symptomatic discomfort of the workers and especially the nasosinusal complications that may occur.

In view of the important socioeconomic impact of occupational diseases for workers and for the society in general, a multiprofessional approach is becoming more and more important, with the participation not only of professionals in the health area but also of engineers, hygienists, social assistants, and psychologists.

\section{REFERENCES}

1. Bagatin E, Costa EA. Doenças das vias aéreas superiores. J Bras Pneumol. 2006;32(Supl 1):S17-S26.

2. Slavin RG. Occupational rhinitis. Ann Allergy Asthma Immunol. 2003;90:2-6.

3. Shusterman D. Upper respiratory tract disorders. In: LaDou J, editor. Occupational and environmental medicine. 2nd ed. Stanford CT: Appleton and Lange 1997. p.291304.

4. Brasil. Ministério da Saúde. Doenças relacionadas ao trabalho: manual de procedimentos para os serviços de saúde. Brasília, DF: Ministério da Saúde; 2001. p.310-62. [Série A. Normas e Manuais Técnicos, 114].

5. Galvão CES. Asma e Rinite Ocupacionais: Visão Imunoalérgicas. Rev Bras Alerg Imunopatol. 2010:33(1);02-07.

6. Della Giustina TBA, Pereira MRG, Costa EA, Seligman J, Ibanez RN, Nudelmann AA. Guia das doenças ocupacionais otorrinolaringológicas. Rev Bras Otorrinolaringologia Supl Cad Debates [periódico na Internet] 2003 [cited 2004 Jan 2];69(1):1-24. (Available from: http://www.rborl.org.br/ suplementos/detalhes_debates.asp?id=14). 
7. Spiegel JR, Sataloff RT. Cancers of the head and neck. In: Harber P, Schenker MB, Balmes JR, editors. Occupational and environmental respiratory disease. St Louis: Mosby Yearbook; 1996. p. 276-90.

8. Slavin RG. Occupational rhinitis. Ann Allergy Asthma Immunol. 2003;90:2-6.

9. Bardana EJJr. Occupational asthma and related respiratory disorders. Dis month. 1995;41:143-99.

10. Brasil. Ministério da Saúde. Doenças relacionadas ao trabalho: manual de procedimentos para os serviços desaúde. Brasília, DF: Ministério da Saúde; 2001. p.310-62. [Série A. Normas e Manuais Técnicos, 114].
11. Arrais A. Doenças do nariz e seios paranasais. In: Prado FC, Ramos OL, Rothschild HA, editores. Atualização terapêutica: manual prático de diagnóstico e tratamento. $19^{a}$ Ed. São Paulo: Artes médicas; 1999. p.1258-64.

12. Christiani DC, Malo JL. Upper airways involvement. In: Bernstein IL, Chan-Yeun M, Malo JL, Bernstei DI, editors. Asthma in the workplace. 2nded. New York: Marcel Dekker; 1999. p.331-9.

13. Schenker MB, Christiani D, Cormier Y, et al. Respiratory health hazards in agriculture. Am J Crit Care Med. 1998;158:S1-S76. 